\title{
A incompatibilidade sistemática entre o contrato built-to-suit e a Lei de Locações
}

\author{
The systematic incompatibility between built-to-suit contracts \\ and Brazilian Lease Statute
}

\author{
GABRIELA WALLAU RODRIGUES
}

\begin{abstract}
RESUMO
O texto analisa as origens e características do contrato built-to-suit, identificando tratar-se de modalidade negocial de natureza essencialmente mercantil, na qual riscos são inerentemente assumidos pelas partes contratantes. Na sequência, é analisado o marcante dirigismo contratual na legislação locatícia, apontandose os diversos momentos históricos em que ele se acentuou ou mitigou, até chegar-se ao atual regramento previsto na Lei n. 8.245/91. Por fim, é investigada a matriz axiológica da Lei de Locações, concluindo-se pela incompatibilidade entre o contrato built-to-suit e esse sistema, bem como indicando-se algumas contingências decorrentes dessa incongruência.
\end{abstract}

Palavras-chave: Contratos Empresariais. Built-to-suit. Lei de Locações. Análise sistemática.

\begin{abstract}
The text analyses the origins and main characteristics of built-to-suit agreements, identifying that it is essentially a business contract by which risks are taken by both parties. It is also analyzed the several occasions in which Brazilian government has intervened through the promulgation of federal statutes ruling leasing agreements, up until the current system, so-called "Lei de Locações" (Lei 8.245/91). After all, it is identified that the values of the current lease statute are not compatible with the structure of built-to-suit agreements and that brings up some contingencies that are pointed out on the text.
\end{abstract}

Keywords: Business Contracts. Built-to-suit. Lease Statute. Systematic analysis.

\section{INTRODUÇÃO}

Segundo a lógica da relação risco vs. retorno, o empresário, por essência, busca no mercado a realização de atividades negociais que lhe tragam vantagens econômicas, assumindo em contrapartida as suas inerentes contingências. Partindo dessa premissa, o presente trabalho analisa as origens e características do built-to-suit, modalidade contratual de atribuída origem norte-americana, cuja utilização crescente vem sendo observada no mercado brasileiro nas últimas décadas.
Após breve incursão nas matrizes do contrato em comento, o texto propõe o reconhecimento do alto grau de dirigismo contratual presente no sistema da Lei de Locações, indicando a existência de diversos fatores sociais e econômicos que justificaram, no último século $\mathrm{XX}$, a intensa edição de normas que limitassem contratualmente as relações entre locadores e inquilinos, a fim de buscar manter o seu equilíbrio econômico.

Por fim, ressaltando-se a concepção contemporânea de que o sistema jurídico deve manter-se lógico e unitário, propõe-se uma reflexão sobre a matriz

\footnotetext{
a Advogada. Mestre em Direito pela PUCRS. Professora de Direito Empresarial na Graduação em Direito e na Pós-Graduação lato sensu em Direito Empresarial da PUCRS. E-mail: <gabriela@wallaueraad.adv.br>.
} 
axiológica da Lei de Locações (Lei no 8.245/91) e a sua incompatibilidade em relação ao contrato built-tosuit, anotando-se algumas inadequações decorrentes da atual classificação deste contrato como modalidade de locação de imóveis urbanos, segundo expressamente prevê a redação da Lei n⿳0 12.744/12.

Longe de pretender esgotar a listagem de todas as decorrências da sugerida incompatibilidade, o texto visa a provocar uma inicial reflexão sobre os objetivos essencialmente distintos entre o built-to-suit e as demais modalidades locatícias, o que justificaria ter-se dado um tratamento legislativo diferenciado entre si. Por outro lado, agora que já inserido no (con)texto da Lei de Locações, pretende-se ao menos propor uma adequada interpretação jurisprudencial que não confunda essas modalidades negociais, ainda que simbolicamente incluídas no mesmo sistema.

\section{ORIGENS E CARACTERÍSTICAS DO CONTRATO BUILT-TO-SUIT}

Em um contexto social e economicamente tão complexo como o contemporâneo, a hiperespecialização é uma realidade inegável, que acaba por conduzir empresários a cada vez mais delegar aquilo que não esteja estritamente no escopo da sua atividade mercantil, transferindo e alocando responsabilidades.

Por razões como esta, a uma rede de farmácias ou de supermercados, por exemplo, via de regra não interessa dispender recursos próprios (capital, tempo, etc.) nem tampouco assumir diretamente os riscos da aquisição e construção dos imóveis onde venham a ser instaladas as suas unidades. Ocorre que, paradoxalmente, o mesmo referido contexto de massificação exige imóveis padronizados e que observem certas características que especificamente atendam às necessidades peculiares do empreendimento, tais como dimensão, layout, acabamentos e localização.

Por um lado, o contrato de locação de imóveis resolveria ao menos parcela do problema, uma vez que, na condição de locatário, o comerciante afastaria de si os riscos da construção e da deterioração do bem, deixando de imobilizar seu capital. Por outro, seria extremamente difícil encontrar um imóvel que contemplasse exatamente as características físicas exigidas pelo pretendido inquilino.

Diante disso, poder-se-ia sugerir: por que não simplesmente contratar a locação, estipulando de antemão com o locador que este proceda na prévia reforma ou mesmo na construção do imóvel, de acordo com características que atendam às necessidades do futuro inquilino? A solução parece fácil e, embora na prática seja por vezes de fato adotada por alguns investidores, acaba por esbarrar em dispositivos originais da Lei de Locações e desequilibrar economicamente o contrato, uma vez que por certo haveria um investimento vultuoso por parte do locador e, em contrapartida, o locatário, querendo, poderia devolver o imóvel a qualquer tempo, simplesmente pagando a multa pactuada contratualmente - que, diga-se, não pode ser elevada, sob pena de redução pela via judicial ${ }^{1}$. Ou seja, tal operação não justificaria o significativo risco e capital empregados pelo locador.

Melhor alternativa foi então encontrada por investidores e seus consultores jurídicos através da composição de uma outra espécie de contrato, de origem norte-americana ${ }^{2}$, a qual a doutrina e a prática comercial convencionaram ${ }^{3}$ chamar built-to-suit (em livre tradução, "construído para servir", ou "construído para atender às necessidades específicas").

Através deste contrato, o locador atende a todas as especificações de construção ou reforma indicadas pelo inquilino (normalmente o próprio projeto detalhado já é por este alcançado)e, em contrapartida, exige a manutenção do vínculo contratual por longo período (via de regra entre dez e quinze anos), a fim de justificar o investimento realizado ${ }^{4}$, sob pena da aplicação de elevada multa contratual - a qual, não raro, corresponde ao próprio valor de todas as prestações remanescentes (tornando, na prática, inócua a opção de rescisão por parte do locatário).

Ao descrever as principais características dessa modalidade contratual, Scavone Júnior ${ }^{5}$ refere tratar-se de "negócio jurídico no qual uma das partes, o locatário, contrata a construção de imóvel de acordo com as suas necessidades, e o recebe por cessão temporária de uso mediante pagamentos mensais dos valores pactuados". Veja-se que, em texto elaborado antes mesmo da inclusão da previsão legal deste contrato na Lei de Locações, o autor já denominava as partes como "locador" e "locatário", entendendo tratar-se de espécie de contrato de locação.

Como principais vantagens do built-to-suit, podem-se destacar: (a) não imobilização do ativo; (b) contabilização do pagamento periódico como despesa operacional (a título de despesas de aluguel); (c) atendimento ao padrão construtivo e necessidades específicas pré-estabelecidas pelo contratante; (d) transferência dos riscos da construção, manutenção e depreciação ao locador; (e) estabelecimento do contrato a longo prazo; (f) autorização legal para a emissão de recebíveis ${ }^{6}$.

Desde o seu surgimento, a doutrina brasileira muito debateu sobre a natureza do contrato built-to-suit - se modalidade de locação ou contrato atípico não sujeito à incidência das normas da Lei do Inquilinato. Visando 
a solucionar esse impasse, o legislador brasileiro houve por incluir, por meio da Lei $\mathrm{n}^{-}$12.744/12, a previsão desta espécie de contrato no corpo da Lei de Locações (Lei no 8.245/91), modificando a redação do art. 4ำ e inserindo o artigo $54-\mathrm{A}^{8}$, para, em síntese, prever maior liberdade contratual entre as partes, possibilitar a cobrança elevada de multa por devolução antecipada do imóvel (que só não pode ser maior do que o valor das prestações remanescentes - vale dizer, pode ser equivalente) e sujeitar o built-to-suit às disposições procedimentais da referida Lei (ações de despejo, revisional, renovatória e consignatória).

Do texto, percebe-se o esforço do legislador em solucionar os embates doutrinários e jurisprudenciais, buscando preservar a autonomia privada e consagrando que as partes possam determinar condições livremente pactuadas e que estas prevalecerão sobre o dirigismo legal. Contudo, o fato de ter sido previsto que as disposições procedimentais serão das da Lei no ${ }^{\circ}$ 8.245/91, aliado à expressa menção de tratar-se de modalidade de locação, acabou permitindo a manutenção de grande parte das controvérsias, razão pela qual o presente estudo visa a trazer alguns elementos de reflexão sobre a adequação da técnica legislativa em inserir o built-tosuit no sistema da Lei do Inquilinato, vez que esta está teleológica e axiologicamente voltada para a proteção de interesses diversos daqueles que circundam o contrato aqui em análise.

\section{O DIRIGISMO CONTRATUAL E A LEI DE LOCAÇÕES}

O Código Civil brasileiro de 1916, sob forte influência do movimento de codificação francês do início do século XIX e da Escola Pandectista, assentava-se sobre matriz essencialmente liberal, na qual a autonomia das partes era largamente prestigiada, havendo mínima influência do Estado sobre as normas contratualmente estabelecidas entre as partes ${ }^{9}$.

Tal modelo, importado para o contexto brasileiro (então essencialmente rural e agrícola), acabou sendo em seguida revisado, sob os efeitos da acentuada assimetria social e paulatina urbanização ${ }^{10}$. Se a estipulação intersubjetiva de vontades livres era contemplada a partir do voluntarismo que permeava as relações ainda não tão complexas da sociedade pré-industrial, essa perspectiva foi inevitavelmente cedendo espaço a formas contratuais que pudessem acompanhar o fenômeno da massificação das relações sociais e econômicas que marcou o século $\mathrm{XX}$ e adentrou o XXI ${ }^{11}$.

Nesse cenário, foi editado o Decreto no 4.403/22, que pela primeira vez no Brasil tipificou os contratos de locação de imóveis urbanos e passou a dirigir tais relações, impondo uma série de condicionamentos para a sua validade e eficácia, tais como o valor do aluguel, a prorrogação cogente da locação e a vedação ao despejo indiscriminado ou à denúncia vazia ${ }^{12}$.

Desta primeira oportunidade de intervenção do Estado nas relações entre inquilinos e locadores até o modelo que hoje se tem no sistema da Lei $\mathrm{n}^{\mathrm{o}}$ $8.245 / 91$, sucederam-se diversos regramentos que, num movimento pendular, por vezes mitigaram e por muitas outras acentuaram a intervenção do legislador nas relações entre inquilinos e locadores - sempre traçando, numa ou noutra direção, os contornos aplicáveis a essa espécie contratual.

Sinteticamente, descrevem-se os diversos regramentos editados no período ${ }^{13}$ :

a) o Decreto 5.617/28, que revogou o Decreto $4.403 / 22$, retomou a aplicação do regime da locação predial urbana segundo as normas do Código Civil;

b) o Decreto $24.150 / 34$ instituiu a locação comercial e regulou as condições e o processo de renovação dos contratos de locação de imóveis destinados a fins comerciais e industriais, com o objetivo de salvaguardar o fundo de comércio;

c) com a eclosão da segunda guerra mundial e a crise habitacional, seguiram-se diversas normas na tentativa de conter o aumento abusivo dos alugueis e a retomada de forma imotivada, a exemplo do DL 4.598/42, que congelava os alugueis residenciais, e o Decreto 7.959/45, que dispunha sobre o contrato de locação de teatros, impedindo o aumento dos alugueis e as denúncias vazias;

d) no pós-guerra, o DL 9.669/46 regulou a legislação emergencial do inquilinato, aplicável tãosomente aos imóveis urbanos. Ainda no mesmo ano, o DL 9.840/46 tipificou alguns crimes contra a economia popular relativos às locação de prédios, a exemplo do recebimento de aluguel além do valor avençado. A Lei 1.300/50 modificou o decreto de 1946, mas manteve a mesma tônica de regular as locações de imóveis urbanos;

e) durante o período de governo militar, observouse tendência a estimular a construção e a liberação dos valores de alugueis, para que fossem corrigidos e atualizados, a exemplo da Lei 4.494/64, Lei 4.864/65, DL 4/66, DL 6/66, DL 322/67, Lei 5.334/67, Lei 5.441/68, DL 890/69, Lei 6.146/74, Lei 6.014,73, Lei 6.071/74, Lei 6.239/74 e Lei no $1.534 / 77$; 
f) a partir de 1979, eclodiu uma tendência de congelamento e controle dos alugueis, bem como da suspensão/sustação das ações de despejo, por meio da Lei 6.649/79, alterada pelas leis 6.698/79, 7.069/82, 7.335/85 e decretos-lei 2.065/83, 2.283/86, 2.284/86, além da Lei 7.538/86, DL 2.290/86, DL 2.322/87, DL 2.335/87, Lei 7.612/87, Lei 7.730/89, Lei $7.777 / 89$, Lei $7.801 / 89$, Lei $8.030 / 90$, Lei 8.157/91, MP 391/91, MP 295/91 e Lei 8.178/91.

Veja-se que, em um só século, dezenas foram as oportunidades em que o legislador brasileiro interveio nas relações contratuais de locação de imóveis urbanos, tanto residenciais quanto comerciais, determinando seu preço, prazos e inclusive hipóteses de retomada (ou sua absoluta impossibilidade) por parte do locador.

Atualmente, o regramento aplicável dá-se pelo sistema da Lei no 8.241, de 1991, pontualmente alterada em alguns aspectos em $2009^{14}$. Vale lembrar o contexto em que promulgada a referida legislação, início da década de 1990, quando se tinha alto grau de instabilidade e insegurança deflagradas pela inflação galopante e planos até então traçados de forma frustrada na tentativa de estabilizar a economia brasileira. Tudo isso contribuiu para a criação de um texto legal que visava a proteger o interesse das partes - especialmente do locatário - através de normas de ordem pública e caráter cogente ${ }^{15}$ acerca de prazos, condições, garantias e hipóteses de rescisão que não poderiam (e até hoje não podem) ser modificadas ainda que pela livre vontade das partes.

Propondo outro entendimento, Arnaldo Rizzardo ${ }^{16}$, em texto publicado logo após a entrada em vigor da então chamada "nova Lei do Inquilinato", manifestou-se no sentido de que esta seria "acintosamente favorável ao locador", pelo menos no que dissesse respeito ao direito de retomada. Contudo, passadas mais de duas décadas da vigência do texto, a sua análise detida e aplicação jurisprudencial levam a entender que haja forte inclinação favorável ao locatário, o que evidencia-se por normas como: (a) imposição da redução da multa rescisória proporcionalmente ao cumprimento do contrato - art. 4-; (b) vedação à cobrança antecipada dos alugueis - art. 20; (c) nulidade de exigência de dupla garantia - art. 37, § único; (d) nulidade da imposição de obrigação pecuniária para a renovação do contrato, quando a lei a permite art. 45; (e) impossibilidade de retomada imotivada dos imóveis utilizados por hospitais, unidades sanitárias oficiais, asilos, estabelecimentos de saúde e de ensino - art. 53, dentre outras.

De qualquer sorte, quer entenda-se a inclinação do texto legal favorável ao locador, quer ao locatário, é inegável a existência de forte teor de dirigismo contratual, o que, por si só, demonstra a inadequação do contrato built-to-suit - construído sobre modelo de ampla liberdade contratual e assunção de riscos pelas partes - com o sistema da Lei do Inquilinato.

\section{SISTEMA E COMPLEXIDADE: O ALINHAMENTO AXIOLÓGICO DA LEI DE LOCAÇÕES E A INCOMPATIBILIDADE DO BUILT-TO-SUIT}

Traçadas as características gerais do contrato builtto-suit e observado o constante propósito do legislador brasileiro em dirigir as relações estabelecidas entre locadores e locatários, cabe neste tópico realizar algumas ponderações a fim de provocar-se a reflexão sobre a compatibilidade sistemática entre aquele contrato e a atual estrutura da Lei do Inquilinato.

Observa-se desde logo que, neste último século $\mathrm{XX}$, todas as (inúmeras!) ocasiões em que editadas regras para dirigir os contratos de locação tinham, invariavelmente, a busca pela simetria da relação negocial. Industrialização, urbanização, pós-guerra, crise habitacional e inflação galopante estão dentre as diversas motivações que, para retomar o equilíbrio de forças, justificavam a incisiva atuação do Estado em estabelecer normas (inclusive, não raro, de natureza penal) que dirigissem os contratos de locação.

Por outro lado, o surgimento das contratações na modalidade built-to-suit pressupõe cenário diverso. Em primeiro lugar, trata-se de contrato essencialmente empresarial, o que significa a sua formação entre sujeitos que desenvolvem atividade mercantil. Extremamente pertinente, portanto, a observação de Ricardo Lupion ${ }^{17}$, que, ao analisar os deveres de conduta decorrentes da boa-fé objetiva nos contratos empresariais, destaca que este ambiente negocial é especial e naturalmente caracterizado pela concorrência e rivalidade, de forma que a assunção dos riscos é a ele inerente.

Em similar sentido, Nelson Eizirik e Marcus Henriques $^{18}$ referem que "quanto maior a simetria e o poder de barganha das partes contratantes, menor será, em respeito ao princípio da força vinculante dos contratos, o espectro de incidência dos mecanismos legais que permitem a resolução e a revisão contratual". Tal é, por suposição, o cenário em que se entabulam os acordos built-to-suit.

A tipificação dessa modalidade contratual, ora inserida nos artigos $4^{\circ}$ e 54-A da Lei $n^{\circ} 8.245 / 91$ acarreta, no mínimo, o efeito de explicitar a sua classificação como espécie de locação sujeita ao sistema da Lei do Inquilinato. Ainda que o mencionado art. 54-A indique que "prevalecerão as condições 
livremente pactuadas no contrato", diversas serão as contingências decorrentes da interpretação e aplicação desta modalidade negocial. A iniciar pelos aspectos processuais, que o mesmo dispositivo já indica ser diretamente aplicáveis.

Cabe, por exemplo, a renúncia expressa ao direito de renovar compulsoriamente o contrato? A considerar pela estrita redação de que prevalecem as condições pactuadas no contrato, aparentemente sim. Contudo, a análise sistemática dos demais dispositivos da Lei de Locações - notadamente arts. 45, 51 e 71 - tende a indicar que não ${ }^{19}$. Mas, veja-se: não se estaria propriamente dispondo sobre o procedimento da renovação compulsória e, sim, do direito material do locatário em manter a relação contratual em vigor.

A simples menção à salvaguarda da liberdade contratual não tem o condão de afastar a classificação do built-to-suit como modalidade de locação e nem aparenta ter sido essa a intenção do legislador. Os efeitos dessa equiparação acabam por gerar alguns impasses decorrentes de interpretação sistemática. A simples leitura dos parágrafos do mesmo art. 54-A que validam a renúncia antecipada ao direito de revisão e obrigatoriedade do pagamento da multa pactuada, limitada ao valor dos alugueis vincendos - conduzem à seguinte indagação: se a liberdade fosse plena (de acordo com o caput), por que enumerar nos parágrafos até onde ela alcança? Seriam as hipóteses do parágrafo exemplificativas ou exaustivas?

O legislador cuidou de expressamente buscar solução para as divergências sobre o valor da multa e a renúncia ao direito de revisar valor do aluguel. Contudo, diversos outros exemplos podem ainda ser citados, para além dos parágrafos do art. 54-A: exigência de dupla garantia, cobrança antecipada dos alugueis, renúncia ao direito de preferência no caso de alienação do imóvel, exigência de "luvas" para a renovação do contrato, dentre outras. Todas são hipóteses expressamente vedadas pela Lei de Locações. Prevalecerá, no caso, a autonomia privada e as condições pactuadas entre as partes?

Note-se que o sistema jurídico, tecido e permeado por valores comuns, não comporta a análise fragmentada dos seus dispositivos. Nesse sentido, Juarez Freitas ${ }^{20}$, denuncia a essencialidade das noções de sistema e complexidade, já que toda aplicação do Direito é necessariamente sistemática. O autor destaca que o intérprete sistemático deve ter sempre em mente a impossibilidade de adotar unilateralismos e simplificações reducionistas, tendo, muito antes, a visada de conjunto torna cognoscível o Direito em sua riqueza valorativa. Reforça que o todo é maior do que as partes (e deve ser, também, melhor), de modo a transcender o método de simplesmente decompor-se o sistema em elementos simples, ressaltando que o pensamento apto a dar conta da sua imanente complexidade há de mostrar-se dialógico em todas as suas etapas.

Ou seja, ao aplicar-se o art. 54-A, estar-se-á levando inevitavelmente em conta todos os valores imantados pela Lei de Locações, como sistema ${ }^{21}$ - o que pode conduzir a equivocadas conclusões. Ainda nessa proposta de rompimento com o pensamento iluminista fragmentário, o transdisciplinar pensador francês Edgar Morin, com forte matriz pascaliana, propõe uma (necessária) reforma de pensamento, abandonando-se a fragmentação (tipicamente cartesiana) e buscando-se o pensamento do complexo (complexus $=$ o que é tecido junto $)^{22}$.

Pietro Perlingeri ${ }^{23}$ também refere que a solução para cada controvérsia "não pode mais ser encontrada levando em conta simplesmente o artigo de lei que parece contê-la e resolvê-la, mas antes, à luz do inteiro ordenamento jurídico, e, em particular, seus preceitos fundamentais, considerados como opções de base que o caracterizam".

Percebe-se, portanto, que a ciência jurídica contemporânea supera a concepção do ordenamento como fragmentário, passando a impor uma releitura sistêmica, afastando por completo a possibilidade de uma interpretação (e consequente aplicação) cartesiana $^{24}$. Ricardo Aronne ${ }^{25}$, nesse sentido, refere que a malha jurídica contemporânea perfaz um sistema à medida que, no seu conjunto, "todos os seus componentes se comunicam [...] para que não se vislumbrem como significantes vazios, em face da intersubjetividade que lhes reveste de significado, no que consiste a defendida noção de unidade e seu sentido axiológico".

Em especial no que diz respeito à interpretação e aplicação do direito comercial, Jorge Lobo ${ }^{26}$ destaca a necessidade de atenção do intérprete às particularidades destas relações negociais, especialmente em decorrência do intenso tráfego mercantil, sendo absolutamente indispensável que o estudioso se aprofunde no exame de sua gênese, no estudo dos fatos econômicos que lhe deram origem.

Eis porque, em 2012, por ocasião da I Jornada de Direito Comercial27, restou aprovado o Enunciado $\mathrm{n}$ - 21, o qual indica que "nos contratos empresariais, o dirigismo contratual deve ser mitigado, tendo em vista a simetria natural das relações interempresariais". Vale dizer, o risco assumido pelas partes, que presumidamente estão ou deveriam estar bem informadas das contingências do negócio, é elemento que faz destoar o built-to-suit das modalidades de locação previstas no sistema da Lei do Inquilinato. 
Veja-se, por fim, que mesmo nas hipóteses aparentemente solucionadas pela Lei, como no caso do $\S 1^{\circ}$ do art. 54-A (validade da cláusula de renúncia à ação revisional), a simbólica classificação do built-tosuit como modalidade contratual sujeita ao sistema da Lei no 8.245/91 pode ainda gerar distorcida aplicação prática do seu conteúdo.

Analisando a Lei de Locações, Arnoldo Wald ${ }^{28}$ defende, desde a década de 1970, que independentemente da existência de cláusula contratual que preveja regras para o aumento progressivo das prestações, há a possibilidade de judicialmente serem revistos os valores estipulados entre as partes quando o desequilíbrio for expressivo, sob a justificativa de que o aluguel mensal deve corresponder proporcionalmente ao valor venal do imóvel, o que, independentemente dos índices de correção monetária ou critérios estabelecidos entre as partes, poderá variar no curso do contrato.

Contudo, no caso do built-to-suit, ainda que haja drástica valorização ou desvalorização do imóvel, pode esta ser tomada, assim como nas locações em geral, como base para justificar a revisão judicial dos valores do contrato, aplicando-se o art. 19 da Lei de Locações? Entende-se que não. No built-to-suit, a referência para a estipulação da remuneração periódica não é, pelo menos não de forma direta, o valor do imóvel e sim o valor do investimento realizado pela contratada. Este, diferentemente do valor venal do imóvel, será invariável no curso da contratação.

Em síntese, sendo o contrato em comento motivado por razões geneticamente diversas das que impelem as locações de imóveis urbanos em geral, faz-se necessário que o intérprete pondere sobre essa dissonância e consequente incompatibilidade com os valores, princípios e regras que regem o inquilinato.

\section{CONCLUSÃO}

Analisadas as características gerais do contrato built-to-suit e a matriz axiológica da atual Lei de Locações, conclui-se pela existência de incompatibilidades sistemáticas entre ambos, o que acarreta inevitavelmente algumas contingências que ora terão de ser solucionadas pelo intérprete.

Ao definir, pela redação do art. 54-A da Lei no 8.245/91, o contrato em comento como modalidade de locação urbana, o legislador brasileiro - assim como já o tinha feito em relação ao contrato de locação em shopping center - deixou clara a sua submissão ao sistema de valores presente na Lei do Inquilinato, o qual, como se viu, prima por forte dirigismo contratual e mitigação da liberdade contratual.
Ocorre que, diferentemente do que se percebe nas locações residenciais e mesmo nas locações empresariais tradicionais, o built-to-suit pressupõe a alocação de riscos entre as partes, surgida em contexto de presumida inexistência de assimetria econômica ou informacional, o que exige a liberdade contratual como ferramenta a viabilizar a correta equação dessa contratação.

Identificadas, portanto, algumas das contingências decorrentes dessa incompatibilidade sistemática, conclui-se, pois, que em vez de introduzir o builtto-suit na previsão do art. 54-A, poderia o legislador brasileiro ter-se valido da mesma técnica adotada em relação ao contrato de arrendamento mercantil, por exemplo, prevendo sua expressa insubordinação às limitações da Lei no 8.245/91, conforme rol excludente do seu art. $1^{\circ}$. Contudo, não tendo-o feito, importa neste momento realizar uma adequada interpretação e aplicação concreta dos dispositivos legais, de modo a reconhecer as diferentes matrizes entre o built-tosuit e as locações em geral, ainda que simbolicamente incluídas no mesmo sistema.

\section{REFERÊNCIAS}

ARONNE, Ricardo. Sistema jurídico e unidade axiológica: os contornos metodológicos do Direito Civil-Constitucional. In: BRASIL. Superior Tribunal de Justiça. Biblioteca Digital Jurídica - BDJur. Disponível em: <http://www.bdjur.stj.gov.br>. Acesso em: 10 maio 2008.

BENEMOND, Fernanda Henneberg. Contratos Built-to-Suit. Coimbra: Almedina, 2013.

BUZAID, Alfredo. Da Ação Renovatória e das demais ações oriundas de contrato de locação de imóveis destinados a fins comerciais. São Paulo: Saraiva, 1988.

CONSELHO DA JUSTIÇA FEDERAL. I Jornada de Direito Comercial, [23-24 de outubro de 2012, Brasília]. Brasília: Conselho da Justiça Federal, Centro de Estudos Judiciários, 2013. Disponível em: <http://www.cjf.jus.br/>. Acesso em: 2 set. 2014.

EIZIRIK, Nelson; HENRIQUES, Marcus de Freitas. Notas sobre a revisão dos contratos. In: ESTEVEZ, André Fernandes; JOBIM, Marcio Felix. Estudos de Direito Empresarial: homenagem aos 50 anos de docência do Professor Peter Walter Ashton. São Paulo: Saraiva, 2012. p. 222.

FREITAS, Juarez. A interpretação sistemática do Direito. 4. ed. São Paulo: Malheiros, 2004.

FIGUEIREDO, Luiz Augusto Haddad. Built to Suit. In: Revista de Direito Imobiliário, São Paulo: Revista dos Tribunais, v. 72, 2012.

LOBO, Jorge. Interpretação do Direito Comercial. In: Revista de Direito Privado, São Paulo: Revista dos Tribunais, v. 5, jan. 2001.

LUPION, Ricardo. Boa-fé objetiva nos contratos empresariais: contornos dogmáticos dos deveres de conduta. Porto Alegre: Livraria do Advogado 2011.

MORIN, Edgar. A cabeça bem feita: repensar a reforma, reformar o pensamento. Trad. Eloá Jacobina. 11. ed. Rio de Janeiro: Bertrand Brasil, 2005.

MORIN, Edgar. Introdução ao pensamento complexo. Lisboa: Instituto Piaget, 1991. 
PACHECO, José da Silva. Tratado das locações, ações de despejo e outras. 11. ed. São Paulo: Revista dos Tribunais, 2000.

PERLINGERI, Piero. Perfis do Direito Civil. Trad. Maria Cristina de Cicco. 2. ed. Rio de Janeiro: Renovar, 2002.

RIZZARDO, Arnaldo. A nova Lei do Inquilinato. In: Revista dos Tribunais, v. 683, p. 7, set. 1992.

SANTOS, Boaventura de Sousa. Um discurso sobre as ciências. 4. ed. São Paulo: Cortez, 2006.

SCAVONE JUNIOR, Luiz António. Direito Imobiliário: Teoria e Prática. 3. ed., rev. e atual. Rio de Janeiro: Forense, 2011.
SÖHNGEN, Clarice Costa. Hermenêutica e Linguística. In: ARONNE, Ricardo. Direito Civil-Constitucional e Teoria do Caos: estudos preliminares. Porto Alegre: Livraria do Advogado, 2006.

TIMM, Luciano. Contratos no Direito Brasileiro. In: Direito \& Justiça. Porto Alegre, v. 39, n. 2, jul.-dez. 2013.

TUCCI, Rogério Lauria; AZEVEDO, Alvaro Villaça. Tratado da Locação Predial Urbana. São Paulo: Saraiva, 1980.

WALD, Arnoldo. Arbitramento Judicial em Locação Comercial. In: Revista de Processo, São Paulo: Revista dos Tribunais, v. 5, jan. 1977.

\section{NOTAS}

${ }^{1}$ A redação original do art. 4º da Lei de Locações (Lei n⿳o 8.245/91), antes das alterações introduzidas pela Lei $\mathrm{n}^{\mathrm{O}}$ 12.744/12, era: “Art. 4을 Durante o prazo estipulado para a duração do contrato, não poderá o locador reaver o imóvel alugado. O locatário, todavia, poderá devolvê-lo, pagando a multa pactuada, proporcionalmente ao período de cumprimento do contrato, ou, na sua falta, a que for judicialmente estipulada". Combinada com o art. 413 do Código Civil ("Art. 413. A penalidade deve ser reduzida equitativamente pelo juiz se a obrigação principal tiver sido cumprida em parte, ou se o montante da penalidade for manifestamente excessivo, tendo-se em vista a natureza e a finalidade do negócio"), a redação conduz à impossibilidade da estipulação de penalidade excessivamente elevada, bem como ao risco de, judicialmente, reduzir-se o valor pactuado a título de cláusula penal rescisória. O Superior Tribunal de Justiça, nesse sentido, já decidiu: "RESP - CIVIL - LOCAÇÃO - MULTA - VALOR - A antiga parêmia - o contrato faz lei entre as partes - hoje, devido ao sentido social da norma jurídica precisa ser analisada 'cum gnamis salis'. (...) Consequentemente, impõe-se a redução da multa compensatória aos limites do razoável, aplicando-se para tanto 'as regras de experiência comum subministradas pela observação do que ordinariamente acontece' (art. 335, CPC). E nesse prisma, conforme já se destacou, o normal é a afixação da multa compensatória no equivalente a três meses de aluguel, portanto ficando adotado tal limite". (Superior Tribunal de Justiça - STJ. Sexta Turma. REsp 187492/SP. Rel. Min. Luiz Vicente Cernicchiaro. J. 15 dez. 1998. In: DJ 8 mar. 1999, p. 263; LEXSTJ v. 119. p. 236).

2 Fernanda Benemond refere que esta modalidade contratual foi largamente difundida no exterior a partir da década de 1950 , primeiramente nos Estados Unidos e, em seguida, na Europa e Ásia. No Brasil, o interesse pela adoção do built-to-suit teve como alavanca a edição da Lei $\mathrm{n}$. 9.514/97, que, ao possibilitar a emissão de recebíveis, expandiu as formas de investimento no mercado de capitais, tornando os negócios imobiliários especialmente atrativos. (BENEMOND, Fernanda Henneberg. Contratos Built-to-Suit. Coimbra: Almedina, 2013).

3 Vale mencionar, a título de informação, que há ocasionalmente outras nomenclaturas também utilizadas pela doutrina, tais como purpose built (BENEMOND, Fernanda Henneberg. Contratos Built-to-Suit. Coimbra: Almedina, 2013), sendo, contudo, o termo built-to-suit o mais consagrado e, portanto, utilizado indistintamente para os fins do presente estudo.

4 "O built-to-suit, a nosso ver, é o contrato em que uma parte, mediante futura remuneração periódica compatível com a amortização dos investimentos que fará, obriga-se a executar (construir por si ou por terceiros), em imóvel sob o seu domínio, que venha a adquirir (por solicitação ou não) ou sobre o qual possa construir e explorar, obra encomendada ou sob medida, para dá-la, por um prazo mínimo, ao uso e gozo da outra parte". (FUIGUEIREDO, Luiz Augusto Haddad. Built to Suit. In: Revista de Direito Imobiliário. v. 72. São Paulo: Revista dos Tribunais, 2012. p. 161)

${ }^{5}$ SCAVONE JUNIOR, Luiz António. Direito Imobiliário: Teoria e Prática. 3. ed., revista e atualizada. Rio de Janeiro: Forense, 2011. p. 944.

${ }^{6}$ Lei n. 9.514/97, art. 6o: "O Certificado de Recebíveis Imobiliários - CRI é título de crédito nominativo, de livre negociação, lastreado em créditos imobiliários e constitui promessa de pagamento em dinheiro".

7 Art. 4 - Durante o prazo estipulado para a duração do contrato, não poderá o locador reaver o imóvel alugado. Com exceção ao que estipula o $\S 2^{\mathrm{o}}$ do art. 54-A, o locatário, todavia, poderá devolvê-lo, pagando a multa pactuada, proporcional ao período de cumprimento do contrato, ou, na sua falta, a que for judicialmente estipulada.
8 Art. 54-A. Na locação não residencial de imóvel urbano na qual o locador procede à prévia aquisição, construção ou substancial reforma, por si mesmo ou por terceiros, do imóvel então especificado pelo pretendente à locação, a fim de que seja a este locado por prazo determinado, prevalecerão as condições livremente pactuadas no contrato respectivo e as disposições procedimentais previstas nesta Lei. § $1^{\text {O }}$ Poderá ser convencionada a renúncia ao direito de revisão do valor dos aluguéis durante o prazo de vigência do contrato de locação. § $2^{\mathrm{O}}$ Em caso de denúncia antecipada do vínculo locatício pelo locatário, comprometese este a cumprir a multa convencionada, que não excederá, porém, a soma dos valores dos aluguéis a receber até o termo final da locação. $\S 3^{\circ}$ (VETADO).

9 Para Luciano Timm, "nesse período, grande era o respeito do legislador à autonomia da vontade das partes e não havia bases legais para a interferência na regulação do contrato pelo Estado, a não ser em casos de vício de consentimento (erro, dolo, coação, etc.). Esse ficou conhecido como o modelo liberal de regulação do contrato". (TIMM, Luciano. Contratos no Direito Brasileiro. In: Direito \& Justiça. Porto Alegre, v. 39, n. 2, jul.-dez. 2013, p. 225).

10 "A aplicação destas ideias [liberais], na prática quotidiana dos negócios jurídicos, foi aos poucos revelando que o êxito da liberdade contratual dependia essencialmente da igualdade econômica dos indivíduos. Já nos albores do século XIX surge a era do industrialismo, caracterizada pela formação e desenvolvimento dos grandes capitais. Com o surto do capitalismo começam a desvanecer-se as doces esperanças da economia liberal, que criou, ao lado de homens fortes, em cujas mãos se concentraram grandes riquezas, uma massa de indivíduos fracos e isolados, obrigados a contratar num plano desigual, em que ficaram sujeitos à prepotência do poderoso. A economia livre converte-se assim em economia de opressão. O contrato deixa de ser o resultado do livre acordo de vontades para tornar-se tributo de sujeição do economicamente mais fraco ao império do economicamente mais forte. Atendendo a essa desigualdade econômica, geradora de graves injustiças sociais, o Estado resolve intervir no domínio dos contratos, abandonando sua atitude interior de passividade". (BUZAID, Alfredo. Da Ação Renovatória e das demais ações oriundas de contrato de locação de imóveis destinados a fins comerciais. São Paulo: Saraiva, 1988. p. 7).

11 "Já no século XX e XXI, a influência maior no direito contratual brasileiro vem do direito europeu (como no caso da regulação da relação de consumo, da locação de imóvel urbano, do trabalho) - e particularmente do direito italiano e português no Código Civil de 2003 -, bem como do direito norte-americano para alguns contratos especiais (sociedade anônima, antitruste, mercado de capitais, seguros, alienação fiduciária, franchising, leasing, etc.). (TIMM, Luciano. Contratos no Direito Brasileiro. In: Direito \& Justiça. Porto Alegre, v. 39, n. 2, jul.-dez. 2013. p. 225).

${ }^{12}$ PACHECO, José da Silva. Tratado das locações, ações de despejo e outras. 11. ed. São Paulo: Revista dos Tribunais, 2000. p. 188

13 Cf. TUCCI, Rogério Lauria; AZEVEDO, Alvaro Villaça. Tratado da Locação Predial Urbana. São Paulo: Saraiva, 1980. p. 3-10; PACHECO, José da Silva. Tratado das locações, ações de despejo e outras. 11. ed. São Paulo: Revista dos Tribunais, 2000. p. 187-190.

${ }^{14}$ Alterações operadas pela Lei n. 12.112/09, nomeada por alguns "Nova Lei do Inquilinato", conquanto as modificações não tenham sido tão extremas, permanecendo a estrutura e os objetivos da Lei, substancialmente, os mesmos.

15 Art. 45, Lei 8.245/91: "São nulas de pleno direito as cláusulas do contrato de locação que visem a elidir os objetivos da presente lei, notadamente 
as que proíbam a prorrogação prevista no art. 47, ou que afastem o direito à renovação, na hipótese do art. 51 , ou que imponham obrigações pecuniárias para tanto".

16 RIZZARDO, Arnaldo. A nova Lei do Inquilinato. In: Revista dos Tribunais, v. 683, p. 7, set. 1992. Descreve o autor: "O espírito do legislador visou à dinamização das locações, de modo a serem colocados no comércio locatício os imóveis ociosos, partindo o projeto das sugestões da classe dos locadores, cujas ideias iniciais eram bem mais drásticas, com possibilidade, inclusive, de no curso da ação, impor o juiz, dentro de certa margem, o valor locatício indicado pelo retomante. É a nova lei acintosamente favorável ao locador, pelo menos nos aspectos que tratam diretamente da retomada, primando, em alguns dispositivos, pela inconstitucionalidade."

17 LUPION, Ricardo. Boa-fé objetiva nos contratos empresariais: contornos dogmáticos dos deveres de conduta. Porto Alegre: Livraria do Advogado, 2011. p. 139.

18 EIZIRIK, Nelson; HENRIQUES, Marcus de Freitas. Notas sobre a revisão dos contratos. In: ESTEVEZ, André Fernandes; JOBIM, Marcio Felix. Estudos de Direito Empresarial: homenagem aos 50 anos de docência do Professor Peter Walter Ashton. São Paulo: Saraiva, 2012. p. 222.

19 Nesse sentido, Scavone Júnior: “o direito à renovação compulsória do contrato, respeitados os requisitos dos arts. 51 e 71 da Lei 8.245/91, não pode ser afastado no contrato 'built-to-suit', a teor do art. 45 da mesma Lei”. (SCAVONE JUNIOR, Luiz António. Direito Imobiliário: teoria e prática. 3. ed., revista e atualizada. Rio de Janeiro: Forense, 2011. p. 944).

${ }^{20}$ FREITAS, Juarez. A interpretação sistemática do Direito. 4. ed. São Paulo: Malheiros, 2004. p. 63.

21 "Verifica-se, nos estudos saussurianos, a partir da questão da identidade do signo linguístico, uma profunda reflexão sobre as relações que acontecem em um sistema linguístico. (...) O valor linguístico, portanto, resulta de dois tipos de relação: relação do significado com o significante e relação do signo com os outros signos do sistema". (SÖHNGEN, Clarice Costa. Hermenêutica e Linguística. In: ARONNE, Ricardo. Direito Civil-Constitucional e Teoria do Caos: Estudos Preliminares. Porto Alegre: Livraria do Advogado, 2006. p. 181).

22 Para Morin, a "virtude sistêmica" é: "a) ter colocado no centro da teoria, com a noção de sistema, não uma unidade elementar discreta, mas uma unidade complexa, um 'todo' que não se reduz à 'soma' das suas partes constitutivas; b) ter concebido a noção de sistema, nem como uma noção 'real' nem como uma noção puramente formal, mas como uma noção ambígua ou fantasma; c) situar-se a um nível transdisciplinar, que permite simultaneamente conceber a unidade da ciência e a diferenciação das ciências, não apenas segundo a natureza material do seu objeto, mas também, segundo os tipos e as complexidades dos fenômenos de associação/organização. Neste último sentido, o campo da teoria dos sistemas e, não apenas mais vasto do que o da cibernética, mas de uma amplitude que se estende a todo o cognoscível" (MORIN, Edgar. Introdução ao Pensamento Complexo. Lisboa: Instituto Piaget, 1991. p. 24-25). Em outra oportunidade, Morin apresenta os princípios vinculados ao pensamento complexo, quais sejam: a) Princípio sistêmico (organizacional): conhecimento das partes ligado ao conhecimento do todo; b) Princípio hologrâmico: a parte representa o todo; c) Princípio do circuito retroativo (feedback): a causa age sobre o efeito e o efeito sobre a causa; d) Princípio do circuito recursivo: produtos e efeitos são eles mesmos produtores e causadores deles mesmos; e) Princípio da autonomia/independência (auto-organização): autonomia é inseparável da dependência do meio; f) Princípio dialógico: inseparabilidade de noções contraditórias; g) Princípio da reintrodução do conhecimento em todo o conhecimento: todo conhecimento é uma reconstrução/tradução feita por uma mente/cérebro, em uma cultura e época determinadas. (MORIN, Edgar. A cabeça bem feita: repensar a reforma, reformar $o$ pensamento. Trad. por Eloá Jacobina. 11. ed. Rio de Janeiro: Bertrand Brasil, 2005. p. 93-96).

23 PERLINGERI, Pietro. Perfis do Direito Civil. Trad. Maria Cristina de Cicco. 2. ed. Rio de Janeiro: Renovar, 2002. p. 5.

24 "Em Descartes, uma das regras do Método consiste precisamente em 'dividir cada uma das dificuldades... em tantas parcelas quanto for possível e requerido para melhor as resolver'. A divisão primordial é a que se distingue entre 'condições iniciais' e 'leis da natureza'. As condições iniciais são o reino da complicação, do acidente e onde é necessário seleccionar as que estabelecem as condições relevantes dos factos a observar; as leis da natureza são o reino da simplicidade e da regularidade, onde é possível observar e medir com rigor. Esta distinção entre condições iniciais e leis da natureza nada tem de "natural". Como bem observa Eugene Wigner, é mesmo completamente arbitrária. No entanto, é nela que assenta toda a ciência moderna". (SANTOS, Boaventura de Sousa. Um discurso sobre as ciências. 4. ed. São Paulo: Cortez, 2006. p. 28).

25 ARONNE, Ricardo. Sistema jurídico e unidade axiológica: os contornos metodológicos do Direito Civil-Constitucional. In: BRASIL. Superior Tribunal de Justiça. Biblioteca Digital Jurídica - BDJur. Disponível em: $<$ http://www.bdjur.stj.gov.br>. Acesso em: 10 maio 2008. p. 16.

26 "Embora uma só e única, é certo que a interpretação do direito comercial, como, aliás, a interpretação do Direito Constitucional e das demais disciplinas, apresenta particularidades devido à natureza das relações decorrentes do intenso tráfego mercantil do mundo moderno e, também, pela insuficiência do ordenamento jurídico, que as mais das vezes, não acompanhou as mudanças radicais e vertiginosas que a sociedade experimentou a partir da década de 50. Destarte, na análise das convenções e tratados internacionais sobre a matéria comercial, das leis, regulamentos, resoluções, circulares e portarias comerciais, dos atos constitutivos das sociedades de pessoas e dos estatutos das sociedades de capitais, da manifestação de vontade dos comerciantes, enfim, na interpretação do direito comercial hodierno, é absolutamente indispensável que o estudioso se aprofunde no exame de sua gênese, no estudo dos fatos econômicos que lhe deram origem, pois, por certo, na maioria das vezes, sobretudo quando se tratar de um novo instituto jurídico (como, no Brasil, o franchising, o cartão de crédito, etc.) o intérprete ver-se-á compelido a um enorme esforço de criação, já que a lei escrita não prevê, claramente, solução para o problema, dele exigindo, portanto, grande tirocínio e capacidade de resposta a uma situação não contemplada pelo legislador". (LOBO, Jorge. Interpretação do Direito Comercial. In: Revista de Direito Privado, v. 5. São Paulo: Revista dos Tribunais, jan. 2001. p. 134).

27 CONSELHO DA JUSTIÇA FEDERAL. I Jornada de Direito Comercial, [23-24 de outubro de 2012, Brasília]. Brasília: Conselho da Justiça Federal, Centro de Estudos Judiciários, 2013. Disponível em: <http:// www.cjf.jus.br/>. Acesso em: 2 set. 2014.

28 "Diante da valorização imobiliária que, nos últimos anos, tem ultrapassado, em determinadas regiões, a alta do custo de vida, a correção monetária, baseada nos índices do Ministério do Planejamento, deixou de ser um instrumento suficientemente sensível para garantir a equivalência das prestações nos contratos de locação, ensejando, assim, um enriquecimento sem causa, para o locatário, e um empobrecimento consequente para o locador. Efetivamente, partindo-se da ideia de que o aluguel mensal deve representar uma percentagem do valor venal do bem alugado, a desproporção no aumento dos valores dos aluguéis e do imóvel implica em distorção do contrato, rompendo, assim, o equilíbrio inicialmente estabelecido pelas partes, e passando a dificultar a própria existência dos contratos a longo prazo, que não se coadunam com este tipo de lesão superveniente." (WALD, Arnoldo. Arbitramento Judicial em Locação Comercial. In: Revista de Processo, v. 5. São Paulo: Revista dos Tribunais, p. 226, jan. 1977.) 